\title{
PROMISES, THREATS, AND THE FOUNDATIONS OF SPEECH ACT THEORY ${ }^{1}$
}

\author{
Antonio Blanco Salgueiro
}

\begin{abstract}
I suggest that promises and threats are similar speech acts and pose analogous problems for Speech Act Theory. After showing that they share the same formal types, I argue against there being purportedly fundamental differences between them in regard to explicitability, deontics, and illocution/perlocution. I conclude that the joint analysis of promises and threats suggests the propriety of a holistic theory of illocutionary acts.
\end{abstract}

Keywords: Promises; Threats; Speech Act Theory; Holism.

\section{Introduction}

Since its beginnings, Speech Act Theory has treated promising as a paradigmatic or prototypical illocutionary act, if not the such act. Austin (1962) uses the promise far more frequently than any other type of speech act to illustrate successively the notions of performative utterance, force and illocutionary act. Similarly, in Searle's early work on speech acts it was assumed that a detailed analysis of promising was a good foundation on which to construct, by extrapolation, a general theory of illocutionary acts that included concepts such as propositional content, preparatory, sincerity and essential conditions (Searle 1965 and 1969); a successful analysis of promising promised to bring with it a systematic theory of speech acts.

Threats are hardly mentioned by Austin (1962), but in Searle's standard classification (Searle 1975) they appear together with promises in the general category of commissives: Illocutionary acts, the illocutionary point of which consists in committing the speaker to a future course of action. In fact, since the 1950s, numerous philosophical studies of promises have also mentioned threats, sometimes with explicit definitions ${ }^{2}$. Most of these papers have taken threats and promises to be close relatives, although the amount of attention paid to one and the other makes it clear which is regarded as the poor relation and which as the rich one. More recently, however, this

\footnotetext{
1 This paper has been supported by the Spanish Ministry of Science and Innovation in the framework of the research projects FFI2008-03092 and FFI2009-08828/FISO.

2 E. g. Grant (1949), Jack (1958), Melden (1956), Harrison (1962), Árdal (1968), Robins (1976), Peetz (1977), Atiyah (1979, 1981), and Cartwright (1984). Note that, in contrast to the usual view of threats and promises as distinct types of commissive, one of the first definitions (Grant 1949: 362) subsumed the former under the latter: "a threat is an unwelcome promise".
} 
view has been challenged. On the one hand, some authors ${ }^{3}$ have treated verbal threats as speech acts that are very different from promises, and much more problematic; although the more moderate simply point to features that they see as more or less fundamental differences between the two as illocutionary acts, ${ }^{4}$ the more radical have suggested that threats are not illocutionary at all, but perlocutionary, and hence dependent on the performance of illocutionary acts, which are more fundamental (Nicoloff 1989; Habermas 1991 and 1999). On the other hand, in a number of recent papers it is convincingly argued, on the basis of meticulous comparative analysis of natural language examples (occurring in actual conversation) as well as subtle conceptual distinctions, that threats and promises have many more similarities than differences, or are perhaps even the two sides of the same coin. ${ }^{5}$ In this paper I defend the latter position: That threats and promises are not just similar, but so intimately related as to constitute an inseparable pair, a conclusion with possibly far-reaching consequences for Speech Act Theory. My approach will be to examine some of the supposed disanalogies or asymmetries that are often drawn attention to in the literature, and evaluate their reality and importance; some difference or differences there obviously must be, if threats and promises are different types of speech act, but how fundamental are they?

As a foretaste of the kind of difficulties we meet in trying to analyse threats, and which do not appear to arise in the case of promises, consider the following Taipei Times report of an action that most of those involved evidently considered as a threat.

\section{Man sent to jail for mailing testicles}

Saturday, Aug 09, 2008

A man from Kaohsiung has been sentenced to four months in prison for sending a threatening letter and two goat testicles to Taipei Mayor Hau Lung-bin, which the Taipei District Court on Thursday ruled was a crime. Chuang Shun-kui, who disapproved of Hau's implementation of a two-step process in Taipei for a referendum vote and the legislative elections earlier this year, sent the letter and testicles to Taipei City Hall last November with the intent of frightening Hau and his staff, the court found. The prison sentence can be converted to a fine and is subject to appeal. Chuang denied that he intended to threaten Hau, arguing that he had exercised his freedom of speech to protest the mayor's decision. He also contended that, as the testicles were edible, they should not frighten anyone. Hau testified that the letter had indeed triggered fears in his office, but expressed his respect for Chuang's differing opinions and said he had no intention to press charges against Chuang. The court ruled that Chuang expressed his discontent in an irrational way and showed no remorse for his actions, and therefore should be sentenced to four months' imprisonment. ${ }^{6}$

\footnotetext{
${ }^{3}$ See, for example, Conison (1997), Habermas (1991, 1999), Nicoloff (1989), and Verbruge et al.(2004).

${ }^{4}$ For Conison (1997), for example, promises generate an obligation, whereas threats do not. See also Verbruge et al. (2004).

5 See Beller (2002); Beller and Bender (2004), Beller, Bender and Kuhnmünch (2005); Castelfranchi and Guerini (2007); Kissine (2008).

${ }^{6}$ Downloaded from http://www.taipeitimes.com/News/taiwan/archives/2008/08/09/2003419841 on July 27th 2009.
} 
The event described in this report has all the ingredients that make the act of threatening difficult to fit into traditional approaches to speech acts. To begin with, it was not a verbal act. Although verbal threats certainly exist, even as conventional formulae such as "Your money or your life!" or "You'll pay for this!", threats are not necessarily, or even typically, verbal. In this case, the main vehicle of the threat appears to have consisted in the action of sending the threatened party a pair of goat testicles. Moreover, this act was not only not verbal, but also appears not to conform to any conventional non-verbal semiotic code; rather, it appears to have been an original if extravagant improvisation. In fact, the menacing nature of the act of sending the testicles depended heavily on the special characteristics of its context: In another context, it could have had an entirely different meaning (e.g. as a fond gift from someone who knows of the receiver's weakness for testicle soup), or no meaning at all. Even though a salient part of the context was a letter, i.e. a true linguistic act, this letter seems not to have included any verbal threats as such, but only hostile expressions (accusations, and possibly insults and other expressions of enmity) such as to create a context in which the testicles were taken as a threat. ${ }^{7}$ Secondly, certain perlocutionary effects seem to be intrinsic to threats. For an act to count as a threat, it would seem to be necessary for its purpose to be to intimidate or cow the person threatened, which raises the question of whether it is an illocutionary or perlocutionary act. In the present case, moreover, the agent, Chuang, denied that he threatened anyone, even though Mayor Hau and his staff, the district prosecutor, the reporter and, probably, most of the Taipei Times' readers all assumed that he did perform an act of threatening, whatever he may have said later. It thus seems to be a complex network of contextual relationships, and not just the private mental states of those involved, that make an act a threat (although it may also be necessary to accept the possibility of inferring threatening intentions regardless of a posteriori denial of such intent).

The remainder of this article is organized as follows. In section 2 I show that promises and threats share the same formal types (which constitutes prima facie evidence of their close relationship). In the following sections I argue against some of the purportedly fundamental differences between promises and threats that have been brought forward in the literature: Specifically, differences in explicitability (section 3), deontics (section 4) and in illocutionary versus perlocutionary nature (section 5). Finally, in section 6, and further to my earlier criticism of the foundations of orthodox Speech Act Theory (Blanco Salgueiro 2004, 2007 and 2008), I use some of these results on promises and threats to support some proposals regarding the methodology of this area of pragmatics.

\footnotetext{
${ }^{7}$ In another report of the same events it is stated that Chuang

blasted Hau for balking at the [Central Election Commission's decision that all ballots be picked up in one single step] and accused Hau of "trampling on the civil rights of Taiwan's people” by advocating the "two-step" voting method. At the end of the letter, he signed the name of a civil group that he coined.
}

Download from http://english.cna.com.tw/SearchNews/doDetail.aspx?id=200804090025 on July 20th 2009. 


\section{Formal types of promise and threat}

The formal differences between promises and threats are minimal, even though, as we shall see in section 3, there can be pronounced differences between the resources for promising and threatening that are actually provided by a natural language. Moreover, although not one but several forms are involved in both promising and threatening, this increases their similarity rather than lessening it, because the formal types of promise are, except for minor details, the same as the formal types of threat.

The most basic illocutionary acts recognized in Speech Act Theory are elementary illocutionary acts of the form $F(P)$, where $F$ is an illocutionary force and $P$ a propositional content. ${ }^{8}$ The simplest promises, and perhaps the most typical, are elementary illocutionary acts performed with utterances such as

(1) (I promise that) next year I'll buy you a car.

I denote the type of such acts by $\mathbf{E P}$ (for "elementary promise"); their form is given by

EP: $\operatorname{Pr}(S \mathrm{~d} a)$,

where $\operatorname{Pr}$ stands for "I promise", $S$ for the speaker (the promiser), $\mathrm{d}$ for doing, and $a$ for the act promised. Typically, elementary promises are made when the promiser offers the person addressed a reward for an action that the latter has already performed to the liking, benefit or satisfaction of the promiser. In another context, elementary promises can be the expression of the pure generosity of the promiser towards a loved-one.

Elementary threats also exist, though to judge by the scant attention paid to them by students of threats they are perhaps not the most interesting for theory. In a typical example, a bully utters elementary threats just to show off or display his or her power, without the immediate receiver having done or shown signs of doing anything to warrant such a threat. Another kind anticipates vengeance: An act of vengeance is threatened in a speech act that, at the same time, constitutes an attempt to initiate vengeance by making the receiver suffer in anticipation of the threatened act. Examples of this latter sort, which may be formalized as

ET (elementary threat): $\operatorname{Th}(S \mathrm{~d} a)$,

where Th stands for "I threaten", include such set phrases as "You'll pay for this!", "I'll kill you!", "You'd better watch out!", or

(2) I'll have your guts for garters!

Both elementary promises and elementary threats - as well as more complex promises and threats, as we shall see below - share with other commissives a

8 This is a simplification, because there are illocutionary acts with simpler content than a

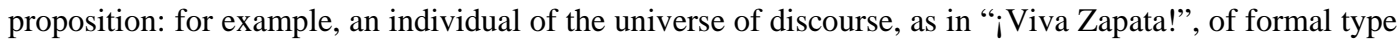
$F(a)$; or null content, as in "Hello", of formal type $F(\varnothing)$. But the simplification is irrelevant to my arguments. For the formalization of orthodox Speech Act Theory, see Searle and Vanderveken (1985) and Vanderveken (1990/91). 
requirement for satisfaction of a condition on their propositional content, which must describe a future action or omission, or a sequence of such actions or omissions, by the speaker.

In classifying promises and threats as commissives, Searle appears basically to have been thinking of elementary promises and threats, in which the speaker commits him or herself to the performance of a future act. In this case the main difference between promises and threats concerns the corresponding sincerity (and perhaps preparatory) conditions: A promised future action is beneficial for the receiver and/or is at least believed to be so by the promiser, the receiver, or both; whereas a threatened future action is detrimental to the receiver and/or is at least believed to be so by the threatener, the receiver, or both. However, the threats that have received most attention, and which are possibly the most typical, are conditional in nature. For example, one of the most cited is that of the bank-robber: "If you don't give me the money, I'll shoot you". Conditional promises are also common: "If you do your homework I'll take you to the pictures".

The difference between elementary and conditional promises or threats is not granted much importance by some authors. In the case of promises, for example, we find passages such as the following.

The distinction between conditional and unconditional promises is not a fundamental one. It simply draws attention to the fact that some promise-sentences contain an 'if...' clause and others do not. There is no more in the distinction than this, because there are tacit conditions even in so-called unconditional promises. [...] Even apparently unconditional promises contain a number of tacit conditions like 'If I am physically capable', etc. These conditions remain tacit simply because everyone takes them for granted. Conditions are only specified when they have to be, i.e. when they are unusual in some way and therefore not 'taken as read'. (Grant 1949: 363-364)

But like Searle when he classifies promises and threats as commissives, Grant here overlooks an important fact: That the most interesting promises and threats are those in which the main objective of the utterance is not commissive (to commit $S$ conditionally or unconditionally to do something), but directive (to get $R$, the receiver, to do something). To forestall such mistakes, it is important to distinguish between what may be called commissive conditional promises or threats, and what may be called directive-commissive conditional promises or threats.

In a commissive conditional promise or threat, the speaker's future action is conditional on the satisfaction of some condition, but the main objective of the promise or threat is not to get $R$ to bring about the satisfaction of that condition, which it is typically not within the receiver's power to do. Possible examples of such promises (3) and threats (4) are

(3) If I win the lottery, (I promise that) I'll buy you a car.

(4) If they make me head of the department, I'll make life impossible for you.

These promises and threats may be represented formally as follows: 
CCP (commissive conditional promise): $\mathrm{P} \rightarrow \operatorname{Pr}(S \mathrm{~d} a)^{9}$

CCT (commissive conditional threat): $\mathrm{P} \rightarrow T h(S \mathrm{~d} a)$

In a directive-commissive conditional promise (5) or threat (6), the main illocutionary point is directive, and $S$ 's commitment to a future action is conditional not just on the fulfilment of the specified condition, but on the receiver's bringing about that fulfilment:

(5) If you give up smoking (I promise you) I'll buy you a car.

(6) If you don't stop seeing Juliet I'll kill you.

Formally,

DCCP (directive-commissive conditional promise): $\operatorname{Re}\left(R \mathrm{~d} a_{1}\right) \wedge\left(\left(R \mathrm{~d} a_{1}\right) \rightarrow \operatorname{Pr}\left(S \mathrm{~d} a_{2}\right)\right)$

DCCT (directive-commissive conditional threat):

$\operatorname{De}\left(R \mathrm{~d} a_{1}\right) \wedge\left(\neg\left(R \mathrm{~d} a_{1}\right) \rightarrow T h\left(S \mathrm{~d} a_{2}\right)\right)$

where Re stands for "I request" and $D e$ for "I demand". Directive-commissive conditional promises and threats warrant a detailed analysis separate from that of elementary promises and threats, and which may possibly include (but not be a part of) the analysis of simply commissive conditional promises and threats. ${ }^{10}$

Note that, in the spirit of Austinian illocutionary holism, the brief analysis given above aims to capture, at least in part, the formal structure of the "total speech act" of promising or threatening in "the total speech situation" (Austin 1962: 148). Accordingly, it matters little how the ingredients of the promise or threat are usually distributed in ordinary oral or written language between strictly linguistic phenomena (the semantic mechanisms of utterances themselves) and other pragmatic mechanisms.

${ }^{9}$ Following Castelfranchi and Guerini (2007) or Beller (2002), it would be more appropriate, in this and the following cases, to consider a biconditional total speech act that incorporates both what is said and what is pragmatically implied, since the speaker who makes the promise "If I win the lottery, I'll buy you a car" or "If you give up smoking, I'll buy you a car", typically wishes also to transmit the idea that the consequent depends totally on the antecedent, i.e. that there will be no car without a win on the lottery, or without the receiver's giving up smoking. I take this into account below in a more detailed formal analysis.

10 Walton (2000) gives a definition of what are here called directive-commissive threats that is typical of orthodox Speech Act Theory in that the commissive aspect is stressed as the essential condition, while the directive aspect is left implicit:

"(Def. Threat)

1. Preparatory Conditions: The hearer has reasons to believe that the speaker can bring about the event in question; without the intervention of the speaker, it is presumed by both the speaker and the hearer that the event will not occur.

2. Sincerity Condition: Both the speaker and the hearer presume that the occurrence of the event will not be in the hearer's interests, that the hearer would want to avoid its occurrence if possible, and that the hearer would take steps to do so if necessary.

3. Essential Condition: The speaker is making a commitment to see to it that the event occur unless the hearer carries out the particular action designated by the speaker.” 
The above considerations show that there is almost total formal parallelism between promises and threats, which share the same basic types and exhibit just two small formal differences between DCCP and DCCT. The first is the presence of the negation in the antecedent part of DCCT: More specifically, whereas in DCCP the antecedent of the commissive part coincides with the content of the directive part, in DCCT it is the negation of the content of the directive part. However, this is a difference that is appropriate in regard to the intuitive similarities and differences of promises and threats. Both directive-commissive promises and directive-commissive threats announce speaker-dependent consequences of the receiver's performing or refraining from performing a particular act: Rewards in the case of promises, penalties in the case of threats. In both cases it is assumed that it will not suffice just to ask or demand that the receiver of the promise or threat perform the desired action or omission, so the speaker tries to increase the attractiveness (to the receiver) of satisfying the request or demand. The difference is that in the case of promises, attractiveness is increased by offering an improvement of the receiver's current situation or prospects, while in the case of threats, attractiveness is increased by offering the possibility of not bringing about a worsening of the receiver's current situation or prospects that is otherwise guaranteed by the threat. $^{11}$

The second formal difference between DCCP and DCCT as formulated above lies in the directive part, which involves requests in the former and demands in the latter. However, this is more a difference of degree than a difference in kind. Directives range in intensity from hints to orders via many other nuances (suggestions, recommendations, requests, petitions, pleas, demands, etc.). The use of requests and demands in the above formulations of DCCP and DCCT is accordingly somewhat arbitrary, and merely serves to stress the different tone of promises and threats.

The close formal parallelism between promises and threats can hardly be mere coincidence. Rather, it seems to indicate an intimate relationship, a fundamental similarity between the language games of promising and threatening that calls for a theoretical explanation. In what follows I explore this relationship further while examining the importance of differences other than those noted above.

\section{Differences in explicitability}

An asymmetry that is not displayed in the above formalization, but which is hinted at in some of the examples presented, concerns the presence, in certain natural languages at least, of conventional markers of promissory illocution that seem neither to be directly applicable to menacing illocution, nor to have obvious analogues for this latter case. In English, it is perfectly normal to make a promise explicit with the words "I promise to .... ", but it is not normal to say "I threaten to ...." in threatening someone. This difference is real, but its importance seems to me to have been exaggerated: There are at least three reasons why it does not make the illocutionary force of threats inexplicitable.

${ }^{11}$ A similar account could be given of the empirical fact that DCCTs often adopt a disjunctive form ("Your money or your life!") that appears to be inadmissible for DCCPs, whereas both DCCPs and DCCTs can adopt not only the canonical forms displayed above, but also conjunctive forms ("Do your homework and I'll take you to the pictures"; "Hang around Juliet and I'll kill you”). This asymmetry is considered by Beller, Bender and Kuhnmünch (2005: 215). 
The first is simply that linguistic and/or paralinguistic devices do exist that make threats explicit, even though the performative use of "threaten" in the first person singular of the present indicative active appears to be ruled out. They include not only the use of an appropriately menacing tone of voice, or of set phrases such as "You'll pay for this!" or "Your money or your life!", but also mechanisms such as the opportunistic response exemplified in Michael Haneke's film Hidden, in which one of the characters asks "Are you threatening me?" and receives the answer "Yes, I'm threatening you". Although some speech act theorists, such as Nicoloff (1989), hold that threats cannot be made explicit in this latter way, the example seems to show quite clearly that they can, and in a perfectly natural manner. Nor does it seem unduly anomalous to use explicitive parenthetical remarks, as in "If I were you I'd leave town - that's a threat"; for in situations of open conflict we do not need to mince our words, and may deem it beneficial to stress the seriousness of our threats by making them more or less explicit. In short, it is simply not true that English does not have at its disposal linguistic devices for explicit menacing illocution, and of course the same goes for other languages. ${ }^{12}$

Secondly, when threats are said not to be explicitable, the intended modal strength of the assertion is often not clear. Certainly, there are social barriers that make it undesirable to be explicit when threatening. Threatening is an intrinsically hostile act, and is generally viewed askance except in certain specific contexts such as the upbringing of children, in which it may acquire a degree of respectability. ${ }^{13}$ Overt threatening may therefore give rise to pragmatic problems by infringing the norms of polite society, to avoid which the typical threat is made non-explicitly, either by insinuation (the receiver is led to suspect but cannot be certain of the speaker's threatening intentions), or by indirect means (the receiver must infer from the context the menace in the speaker's words). ${ }^{14}$ But this is a very weak form of inexplicitability, a merely empirical impediment. Austin (1962: 30, footnote 2) mentioned a counterexample to the similar supposed inexplicitability of insulting: Whereas to say "I insult you" would indeed normally be a peculiar and anomalous way of trying to insult someone, an equivalent mechanism, directly addressing the receiver with the formula "Beleidigung", was current among German students' duelling clubs. In the case of threats, there is in principle nothing to prevent the use of an analogous formula, for example among rival families of the Mafia.

Thirdly, it should not be forgotten that in most of our everyday speech acts we do not employ Austinian canonical forms. Reading certain speech act theorists, one might think that we are usually explicit as regards the force of our speech acts, but this is clearly not so. In this paper, for example, there are probably very few explicit

${ }^{12}$ It may be noted that the explicit negation of a threat -“I'm not threatening you” - is quite usual.

${ }^{13}$ For a discussion of the distinction between legitimate or benign threats and illegitimate or malicious threats, see Kimball (2006) and Walton and Macagno (2007). It may be noted that this "normative" typology, like the formal typology, points to the parallelism between threats and promises, since we can also distinguish between legitimate promises and promises that are illegitimate (shameful, immoral): "I promise I'll kill your husband", "If you sleep with me I’ll give you an alpha”. And as in the formal case, the parallelism is only reinforced by the presence of an asymmetry that is necessary if threats are to be distinguished from promises - in this case, "normal" promises are legitimate, whereas "normal" threats are illegitimate.

${ }^{14}$ Walton (2000) does not distinguish between these different modes of non-explicit threatening. 
illocutionary acts, although all the illocutionary acts there are can I hope be easily recognized as assertions, objections, etc. Griceans, indeed, insist that we can perform paradigmatic communicative acts with content and force in the absence of any conventions, linguistic or otherwise: Acts such as warning (one hominid warns another of the risk he runs beneath a coconut palm by means of gestures imitating a coconut falling on his head) or asking (your flatmate leaves the dirty linen basket in the middle of the sitting room to ask you to load the washing machine). ${ }^{15}$ In short, the fact that the illocutionary force of threats is not generally explicit does not make them abnormal or aberrant as speech acts.

\section{Deontics}

Both those for whom threats and promises are close relatives, and those for whom they are totally dissimilar acts, often accept the existence of a deontic difference between the two: That promises constitutively generate for the speaker an obligation to keep his or her promise, without which obligation no promise has been made, ${ }^{16}$ while threats appear to generate no such obligation, at least with the person threatened. If a threat is not carried out, the person threatened will not complain that the threatener has not kept his word. In section 4.2 I shall argue that this asymmetry between promises and threats is more apparent than real, that both promises and threats harbour deontic content. But before that, in section 4.1, I argue that even a significant difference between the two in this respect would not threaten the foundations of standard or "orthodox" Speech Act Theory.

\subsection{How important would the difference be for Speech Act Theory?}

If threats are not to be absolutely identified with promises, there must obviously be some differences between one and the other. Thus the existence of differences does not necessarily constitute a threat to Speech Act Theory; in particular, it does not necessarily make threats, rather than promises, a threat to Speech Act Theory. Indeed, in not imposing an obligation upon the speaker, threats are more like the majority of speech acts - in particular such paradigmatic illocutionary acts as predictions, congratulations, or requests - than are promises; it is for promises that an explanation of their associated obligation must be given. ${ }^{17}$ What might be threatened by the supposed deontic asymmetry between threats and promises is the idea that they are so similar that

${ }^{15}$ The first example is taken from Bennett (1991), the second from García-Carpintero (1996).

${ }^{16}$ The idea that "I promise"analytically implies "I must" is already present in Austin (1962).

${ }^{17}$ Cfr. Habib (2008). Pragmatics appears to invade the territory of ethics here, although some authors, such as Beller (2002), refer to the apparently weaker obligatoriness of social norms. For authors such as Habermas, the difference between threats and promises centres on a kind of normativity that is supposedly inherent in the latter but not the former. Authors close to Habermas have argued that this framework also applies to certain threats, namely, legitimate threats such as a police agent might address to a bank-robber, and that all other threats are parasitic upon these legitimate ones (Heath 1995, 1996; for a discussion of this, see Corredor 2001). I agree that there is no fundamental difference between threats and promises as regards deontic issues (normativity, generation of obligatoriness, etc.), but the notion that illegitimate threats are parasitic upon legitimate ones seems to me to be totally implausible. If anything, the reverse might be the case. 
any plausible taxonomy of illocutionary acts must necessarily include them both in the same category or family, as does the standard taxonomy of Searle, in which they are both counted as commissives: Illocutionary acts, the illocutionary point of which involves committing the speaker to a future course of action. If we assume that such a commitment is equivalent to accepting an obligation (for Searle, an obligation is really just a specially strong form of commitment), then the problem that for some authors is posed by threats amounts merely to the issue of whether they should be classified as commissives, a question that in principle should not shake the foundations of Speech Act Theory. Since elementary threats are also similar to predictions and announcements, one possible solution would be to reclassify them as assertives with certain special characteristics, such as conditions on their propositional content. It should be pointed out, moreover, that threats are not the only questionable commissives: Declarations of intent, which Searle likewise includes in this category (and which might well embrace elementary threats in a modified taxonomy), seem not always to generate an obligation, at least so strong an obligation as to give the receiver the right to complain if the speaker fails to deliver (consider, for example, "I intend to spend summer in Asturias", addressed to someone whose own plans for the summer in no way depend on those of the speaker). Certainly, Searle's classification is flexible to the extent that illocutionary points can have different degrees of intensity, a property that distinguishes conjectures from assertions among assertives, and requests from demands among directives; but it is not so flexible as to allow threats, declarations of intent or any other commissives to generate no duty at all. Certainly, then, if the supposed deontic asymmetry between threats and promises exists, threats must be reclassified; but this does not undermine the whole edifice of Speech Act Theory.

\subsection{Must the deontic difference be accepted?}

Two kinds of doubts may be voiced in regard to the supposed deontic difference between threats and promises. One concerns whether the generation of obligations is actually, and without qualification, constitutive of promises. ${ }^{18}$ For example, if $S$ discovers, after promising to do $a$, that $R$ is no longer interested in the promised act ( $S \mathrm{~d}$ $a$ ), is $S$ still under an obligation to perform it? This kind of consideration might lead us to refine the assertion that promises generate obligations. However, I shall not go further into this question in this paper; instead, I shall explore the second kind of issue, and ask whether obligations are not also, in fact, a constitutive component of threats, albeit not in the same way or with the same intensity as they are of promises.

Let us start with elementary threats. The prototypical elementary threat is generally assumed to involve essentially just two people, the utterer of the threat and its receiver. In this case, it would seem that the only possible source of obligation must be the threatener's need to maintain his or her credibility, which depends to a large extent on the fulfilment of threats. This need for credibility may not suffice for the threat to generate a moral obligation, but it provides grounds for saying that in an instrumental sense the threatener ought to fulfil his or her threats, or at least has a good reason for fulfilment. This case nevertheless seems to me not to be the most typical, even among

\footnotetext{
${ }^{18}$ This is the question considered by Ärdal (1968).
} 
elementary threats. In the most interesting case, which I believe is also the most typical, there are one or more direct or indirect witnesses of the threat, many of whom are liable to be threatened by the threatener in future, and whose knowledge of the present threat accordingly increases the value, for the threatener, of maintaining credibility. Moreover, the situation is complicated by the possibility that, even though $S$ 's threatened action would harm $R$, it might benefit one or more of the witnesses or other third parties; in which case, the threat could be taken by the potential beneficiaries as an indirect promise, a promise that $S$ would accordingly have acquired an obligation to fulfil. This is just one example of how threats and promises can be intertwined, and of how the nature of such speech acts can depend on factors that are external to both speaker and receiver.

The case of directive-commissive conditional threats is somewhat more complex, although in this case, too, there are instances that only involve the threatener and the threatened party, and others that also involve witnesses or other third parties. In this latter regard, situations of Romeo and Juliet type provide examples of third parties with interests contrary to those of the threatened person: If a Capulet of uncharacteristically moderate bent were merely to threaten to kill Romeo should he come anywhere near Juliet, and to fail to try to carry out his threat when Romeo later approaches her, then other Capulets would undoubtedly complain that he had not been true to his word. Additionally, however, as a number of authors have pointed out, ${ }^{19}$ all conditional threats are associated with a complementary conditional promise and, vice versa, all conditional promises with a complementary conditional threat. For example, if a (rather silly) mother promises "If you do your homework I'll buy you a video game", she implicitly also transmits the threat “If you don't do your homework I won't buy you a video game". Thus a DCCP is really a biconditional ("I'll buy you a video game if and only if you do your homework"), at least if we take into account the total speech act in the total speech situation:

$$
\mathbf{D C C P}^{*} \operatorname{Re}\left(R \mathrm{~d} a_{1}\right) \wedge\left(\left(R \mathrm{~d} a_{1}\right) \rightarrow \operatorname{Pr}\left(S \mathrm{~d} a_{2}\right)\right) \wedge\left(\neg\left(R \mathrm{~d} a_{1}\right) \rightarrow \operatorname{Th}\left(\neg\left(S \mathrm{~d} a_{2}\right)\right)\right)
$$

And in the case of DCCTs, the complementary promise brings with it the corresponding obligations: In threatening to kill Romeo if he comes near Juliet, the moderate Capulet implicitly promises not to kill him if he keeps away from her, and thereby acquires the obligation to keep this promise. Schematically,

$$
\text { DCCT }^{*}: \operatorname{De}\left(R \mathrm{~d} a_{1}\right) \wedge\left(\neg\left(R \mathrm{~d} a_{1}\right) \rightarrow T h\left(S \mathrm{~d} a_{2}\right)\right) \wedge\left(\left(R \mathrm{~d} a_{1}\right) \rightarrow \operatorname{Pr}\left(\neg\left(S \mathrm{~d} a_{2}\right)\right)\right)
$$

A difference between an overt or primary DCCP and the conditional promise implicit in a DCCT is that, as we have already seen in section 2, the incentive offered by the latter is merely that the speaker will refrain from harming the receiver, whereas in the former the incentive is an improvement of the receiver's current situation or prospects. Similarly, whereas the deterrent appealed to in a primary DCCT would harm the receiver, the deterrent appealed to in the conditional threat that is implicit in a DCCP is merely the failure to obtain the reward offered in the explicit promise (it is this

\footnotetext{
${ }^{19}$ For example, Castelfranchi and Guerini (2007), and Beller (2002).
} 
difference in intensity that has led me to retain the weak directive $R e$ rather than the $D e$ of primary threats).

I stress once more that what is important here is the total speech act, regardless of the specific semantic or pragmatic mechanisms that may be employed in typical cases. In the typical DCCT, the threat is expressed explicitly, and the associated directive and complementary promise are implicit; but it is not always so. One of the bank-robbers in Spike Lee's film Inside Man, after threatening to kill the hostages if not given a helicopter to flee in, says "If I get what I want, I won't kill anyone”, or words to that effect, thus expressing the complementary promise explicitly while clearly implying the directive and the threat.

To sum up, it seems that at least directive-commissive conditional promises and threats are intimately associated in such a way that a threat is always accompanied by a promise and vice versa, thereby making obligation as consubstantial to threats as to promises.

\section{Illocution/perlocution: Do threats threaten Speech Act Theory?}

Another supposed asymmetry between promises and threats concerns the distinction between illocutionary and perlocutionary speech acts: Whereas promises are assumed to be paradigmatically illocutionary, the case of threats is not so clear (see Nicoloff 1989; and Habermas 1991 and 1999). Whereas illocution has been variously expounded in terms of notions such as intention (by Grice and followers), convention (by Austin), constitutive rule (by Searle) or norm (by Habermas), perlocution is generally treated as associated with the purely natural or causal, and threats seem to involve perlocutionary features in an essential, or constitutive, rather than a merely usual but contingent way: Specifically, certain usual and apparently typical perlocutionary acts - causing the receiver to feel intimidated, terrified, etc. - appear to form part of what a threat is. This tendency to view threats as part of nature, and promises, by contrast, as part of human language and society, evokes echoes of the classical myth of the Social Contract, of a promise that marks the end of a pre-social, pre-linguistic natural state of perpetual, allonto-all conflict and omnipresent menace; but it is a partial view that exaggerates the differences between threats and promises.

To start with, consider Nicoloff's (1989) argument that the primary use of the verb to threaten, exemplified by "Those clouds threaten a storm", does not directly concern any human action even though, as in this case, it may be relevant to human affairs. It is just this kind of use that I have made of threaten in the title of this section. But to promise can be used in exactly the same way: "This rain promises a good harvest"; "Promises promise success for Speech Act Theory". What Nicoloff appears to insinuate is that in "This rain promises a good harvest" rain is treated anthropomorphically, and "promises" is accordingly metaphorical; whereas in "Those clouds threaten a storm", "threaten” is used not only literally but in its primary sense. I suggest that this linguistic intuition is off the mark, and that in these sentences "threaten" and "promises" are either both being used literally, or, much more probably, both metaphorically. Moreover, it should not be forgotten that threatening is a class of acts, some of which, such as blackmailing or giving an ultimatum, seem to lack any "natural" or even metaphorical use, and to be as essentially linguistic and conventional as promising. 
Turning now to direct consideration of whether perlocution is essential to threats but not to promises, it must be borne in mind that all Searlean directives, by definition, are intended to have certain effects on the receiver: Specifically, their illocutionary point is to modify the receiver's future conduct. That this is part of their illocutionary force as directives gives rise to no particular problems for Speech Act Theory. Thus the speaker's intention of evoking a behavioural response in the receiver is consubstantial to both threats and promises that are directives as well as commissives; granted which, it is difficult to see why an intention to influence the receiver in other ways should not likewise be consubstantial to certain illocutionary forces.

It is thus questionable whether there is any real asymmetry between threats and promises as regards their illocutionary or perlocutionary nature. When we promise, we usually entertain certain purposes involving effects upon the receiver; an elementary promise, for example, is often made to make the receiver feel happy. It might be argued that making the receiver feel happy is a merely contingent effect of promises, that a correct characterization of promises requires no essential mention of perlocutionary goals, whereas mention of the perlocutionary goal of intimidating the hearer is necessary for the correct description of threats. But this does not seem to be tenable. In the first place, the constitutive rules of promising (as given, for example, by Searle (1969)) include the promised action being pleasing to the receiver, and finding something pleasing is intimately related to feeling happy in a way that parallels the way in which threatening someone with something unpleasant is related to alarming and intimidating them. Secondly, although promises can indeed sometimes be uttered out of duty, without a desire to please the receiver, so too threats can also be uttered out of duty, for example by members of the police or the armed forces.

\section{Conclusions}

The main purpose of this paper has been to stress the similarities between two kinds of speech act, promising and threatening, and to reject or minimize the importance of certain asymmetries between them that by some authors have been regarded as fundamental differences. I have argued that threats and promises share the same basic formal types, and that their differences as regards explicitability, deontic value and illocutionary versus perlocutionary nature have been greatly exaggerated. Nevertheless, I have accepted that threats are different from promises, and that their differences are interesting. One quite important difference derives from the fact that things promised are, or are believed to be, beneficial for the receiver whereas things threatened are, or are believed to be, detrimental to the receiver. As a result, the successful fulfilment of promises requires the tacit or explicit acquiescence of the receiver, who can "deactivate" the promise by denying acquiescence either immediately (by saying that he does not want the speaker to perform the promised act, or that he does not want to be left owing the speaker a favour, etc.) or at a later date (for example, by saying that he no longer desires the performance of the promised act). Threats, on the other hand, seem not to be liable to deactivation in this way. In fact, whereas the most effective way for the receiver to deactivate a threat is by means of a counterthreat, a counterpromise reinforces a promise rather than deactivating it. This difference means that whereas promises are essentially intersubjective speech acts, the performance of which involves the active joint participation of both speaker and receiver (as also in the case of betting), 
threats are more unilateral affairs (although the possible role of onlookers and other third parties must not be forgotten); and this in turn means that promises are more difficult to fit into standard Speech Act Theory, which is basically intentionalist, than are threats.

More generally, the above discussion highlights two important failings of traditional versions of Speech Act Theory, showing $a$ ) that successful analysis of speech acts cannot focus solely on the speaker, or even on speaker and receiver, as has been the usual practice; and $b$ ) that different illocutionary forces cannot be successfully analysed separately or in isolation from each other. A satisfactory analysis of all the different types of threat and promise requires a more holistic approach because, as we have seen above, it is necessary to take into account $a$ ) third parties - we might call them "illocutionary spectators" - whose interests may coincide or conflict with those of speaker, receiver, or both; and $b$ ) the fact that promises and threats are constitutively intertwined, forming a single language game (or, more precisely, a family of games, each of which involves both promise and threat). Extrapolating these ideas, it seems plausible that some illocutionary forces, if not all, can only be understood satisfactorily as forming part of a more or less extensive network of forces that are modulated by a multitude of contextual factors. To accept this is to accept a form of illocutionary holism. $^{20}$

\section{References}

Árdal, P.S. (1968) And that’s a promise. The Philosophical Quarterly 18.72: 225-237.

Atiyah, P.S. (1979) Promises and the law of contract. Mind 88.351: 410-418.

Atiyah, P.S. (1981) Promises, morals and law. Oxford: Clarendon Press.

Austin, J.L. (1962) How to do things with words. Oxford: Oxford University Press.

Beller, S. (2002) Conditional promises and threats - Cognition and emotion. Proceedings of the TwentyFourth Annual Conference of the Cognitive Science Society. Mahwah, NJ: Lawrence Erlbaum, pp. 113118.

Beller, S. and Bender, A. (2004) Cultural differences in the cognition and emotion of conditional promises and threats - Comparing Germany and Tonga. In K.D. Forbus, D. Gentner and T. Regier (eds), Proceedings of the Twenty-Sixth Annual Conference of the Cognitive Science Society. Mahwah, NJ: Lawrence Erlbaum, pp. 85-90.

${ }^{20}$ A number of previous studies have pointed in this direction. Beller (2000), Beller and Bender (2004) and Beller, Bender and Kuhnmünch (2005) base their analyses of conditional threats and promises on the premise that they must involve multiple factors and levels of analysis that capture motivation (goals, expectations and incentives), linguistic aspects (formulation and inference), behaviour (action sequences), deontics (obligation and permission), and emotion (affective reactions of joy, relief, anger, etc.). Walton (2000) and Walton and Macagno (2007) suggest that to treat threats as isolated speech acts is mistaken, since they should be understood as forming part of a certain kind of "argument", namely argumentum ad baculum. For Kimball (2006: 90), it is necessary to take an even broader context into account if we are to distinguish between legitimate and illegitimate threats: "This analysis puts the discussion of threats in the context of virtue theory, of human flourishing, and of the kind of social relations it is best to have". 
Beller, S., A. Bender, and G. Kuhnmünch (2005) Understanding conditional promises and threats. Thinking \& Reasoning 11.3: 209-238.

Bennett, J. (1991) How do gestures succeed? In E. Lepore and R. van Gulick (eds.), John Searle and his critics. Oxford: Blackwell, pp. 3-15.

Blanco Salgueiro, A. (2004) Palabras al viento. Ensayo sobre la fuerza ilocucionaria. Madrid: Trotta.

Blanco Salgueiro, A. (2007) Un rompecabezas acerca de la fuerza. In C. Martínez et al. (eds.), Current topics in logic and analytic philosophy. Santiago de Compostela: Universidade de Santiago de Compostela, pp. 53-77.

Blanco Salgueiro, A. (2008) Cómo hacer cosas malas con palabras: Actos ilocucionarios hostiles y los fundamentos de la Teoría de los Actos de Habla. Crítica, Revista Hispnoamericana de Filosofía 40.118: 93-120.

Cartwright, J.P.W. (1984) An evidentiary theory of promises. Mind 93.370: 230-248.

Castelfranchi, C., and M. Guerini (2007) Is it a promise or a threat? Pragmatics \& Cognition 15.2: 277311.

Conison, J. (1997) The pragmatics of promise. Canadian Journal of Law and Jurisprudence 10.2: 273322.

Corredor, C. (2001) A comment on threats and communicative rationality. Theoria 16.40: 147-166.

García-Carpintero, M. (1996) Las ideas, las palabras y las cosas. Barcelona: Ariel.

Grant, C.K. (1949) Promises. Mind 58.231: 359-366.

Habermas, J. (1991) Comments on John Searle: "Meaning, communication and representation”. In E. Lepore and R. Van Gulick (eds.), John Searle and his critics. Oxford: Blackwell, pp. 17-29.

Habib, A. (2008) Promises. Stanford Encyclopedia of Philosophy. Ed. E.N. Zalta. URL = $<$ http:://plato.stanford.edu/entries/promises/>.

Habermas, J. (1999) Wahrheit und Rechtfertigung. Frankfurt am Main: Suhrkamp Verlag.

Harrison, J. (1962) Knowing and promising. Mind 71.284: 443-457.

Heath, J. (1995) Threats, promises and communicative action. European Journal of Philosophy 3.3: 225241.

Heath, J. (1996) Is language a game? Canadian Journal of Philosophy 26.1: 1-28.

Jack, H. (1958) On the analysis of promises. The Journal of Philosophy 55.14: 597-604.

Kimball, R.H. (2006) What's wrong with argumentum ad baculum? Reasons, threats, and logical norms. Argumentation 20: 89-100.

Kissine, M. (2008) From predictions to promises. How to derive deontic commitment. Pragmatics \& Cognition 16.3: 471-491.

Melden, A.I. (1956) On promising. Mind 65.257: 49-66.

Nicoloff, F. (1989) Threats and illocutions. Journal of Pragmatics 13: 501-522. 


\section{Antonio Blanco Salgueiro}

Peetz, V. (1977) Promises and threats. Mind 86.344: 578-581.

Robins, M.H. (1976) The primacy of promising. Mind 85.339: 321-340.

Searle, J.R. (1965) What is a speech act? In M. Black (ed.), Philosophy in America. Ithaca, NY: Cornell University Press. London: Allen and Unwin.

Searle, J.R. (1969) Speech Acts. An Essay in the Philosophy of Language. Cambridge: Cambridge University Press.

Searle, J.R. (1975) A taxonomy of illocutionary acts. In K. Gunderson (ed.), Language, Mind and Knowledge. Minneapolis: University of Minnesota Press.

Searle, J.R., and D. Vanderveken (1985) Foundations of Illocutionary Logic. Cambridge: Cambridge University Press.

Vanderveken, D. (1990/91) Meaning and Speech Acts, 2 vols. Cambridge: Cambridge University Press.

Verbrugge, S., K. Dieussaert, W. Schaeken, and W. Van Belle (2004) Promise is debt, threat another matter: The effect of credibility on the interpretation of conditional promises and threats. Canadian Journal of Experimental Psychology 58.2: 106-112.

Walton, D. (2000) Scare Tactics. Arguments that Appeal to Fear and Threat. Dordrecht: Kluwer.

Walton, D., and F. Macagno (2007) The fallaciousness of threats: Character and ad baculum. Argumentation 21: 63-81.

ANTONIO BLANCO SALGUEIRO is currently Associate Professor at the Department of Logic and Science, Universidad Complutense de Madrid. His previous work concerns the philosophy of mind (in particular the problem of mental content) and the philosophy of language and of linguistics (especially the language-thought relationship and the philosophical foundations of Speech Act Theory). He has published papers on these topics, and a book on illocutionary force in Spanish Palabras al viento. Ensayo sobre la fuerza ilocucionaria. (Madrid: Trotta, 2004). His current research interests centre on specific problems of Speech Act Theory. He is interested in particular in "hostile speech acts", the study of speech acts such as promises and threats, and the illocutionary/perlocutionary distinction.

Address: Departamento de Lógica y Filosofía de la Ciencia, Facultad de Filosofía, Edif. B, Universidad Complutense de Madrid, Ciudad Universitaria, E-28040 Madrid, Spain; e-mail: ablancos@filos.ucm.es 